\title{
CORRESPONDENCE
}

\section{Reactors away}

SIR, - We nuclear technologists have plenty of reason to consider ourselves unloved and misunderstood. On $20 \mathrm{March}$ in Middletown, Pennsylvania, not far from Three Mile Island, some $\mathbf{4 0 0}$ angry local residents bitterly attacked officials of the Nuclear Regulatory Commission over the proposal that the 60,000 curies of $85 \mathrm{Kr}$ still trapped in the containment vessel should be released. This is a necessary first step in decontamination of Three Mile Island. The estimated maximum dose to any resident of Middletown caused by this release would have been $11 \mathrm{mr}$ beta skin dose, $0.2 \mathrm{mr}$ whole body gamma dose - the latter being of the same order as the dose received in a

transatlantic flight.

The local people at the meeting were filled with bitter resentment and mistrust of NRC, as well as a deep, almost hysterical fear of low levels of radiation. I myself do not see how nuclear energy can survive in the long run or possibly in the short run - if the public cannot distinguish between say, a millirem and a million rem.

It is for such reasons that I have urged that reactors be confined, permanently, to a relatively few and rather remote sites. C. Burwell, J. Ohanian, and J. Lane of the Institute for Energy Analysis have shown that 600 large reactors - possibly the number that will be built in the United States by the middle of the next century - could fit on about 100 large sites. Most of these could be expansions of the existing nuclear sites which, surprisingly, are already rather remote.

In heavily populated Europe, there are few remote sites - although even in Denmark such sites can be found on Zeeland.

Nevertheless, even if the sites are not remote, there are many other advantages of clustered siting - better organization on site, security and internal lines of transport for example. It is significant that almost one-half of all the nuclear power to be generated outside the US by 1985 will move from sites containing four or more reactors; three sites have eight or more reactors on them.

The environmental hysteria displayed at Middletown is not confined to low levels of radiation. The litany of incidents involving toxic effluents grows longer each day Seveso, Mississauga, Love Canal. Hardly a nightly TV news broadcast in the United States goes by without another account of people suffering maladies attributed to low levels of industrial toxicants.

I am therefore much taken by Dr Pietro Cappuro's proposal in Clinical Toxicology 13, 325 (1979) "that industrial plants be concentrated in groups, at locations where natural factors such as wind, land contour and water flow provide rapid dilution of toxic effluents". The notion of rather remote, permanent industrial enclaves is not new. It is striking that many of the same arguments that support remote, confined, and permanent siting for nuclear energy are being adduced to support a siting policy for polluting industry in general.

An important element in the proposal for nuclear siting is that each site should be committed, if not in perpetuity, then for a very long time. Low-level radioactive wastes could thereby be handled on site, as is now being done at the large Bruce site in Canada and at the seven TVA nuclear sites. This same imputation of permanence could be exploited for non-nuclear wastes as well. If the sites at which industrial activity continues are also used for disposal of low-level chemical wastes, fiascos such as that of Love Canal, where toxic wastes were nobody's responsibility, would be dealt with rather automatically.

Like nuclear energy, the potentially dangerous chemical technologies demand long-term attention to detail and organizational integrity in return for the benefits they confer. It is striking that a recipe for living with the nuclear Faustian Bargain to confine the enterprise to relatively few, permanent sites - is now recognized as applying to other technologies as well. Perhaps the nuclear enterprise can find some consolation in the growing realization that it is not unique in what it asks of the society in return for the benefits it confers.

Yours faithfully,

Alvin M. Weinberg

Institute for Energy Analysis,

Oak Ridge, Tenn., U.S.A.

\section{Parkinson's trees}

SIR,-R. Moss (Nature, 285: 9) has provided a useful mathematical model to help explain the now well-established (if bureaucratically unpopular) scale effect that results in large organizations being less productive than small ones. Non-mathematical readers may find a simple ecological comparison easier to follow. A tree may be appropriate model. The leaves represent the primary producers or scientists, the branches and trunk the support staff. The ratio of leaf to branch weight can be of the required order, averaging 12.6:10.2 in Picea abies (J. D. Ovington, Advances in Ecological Research, 1, 103 (1962)). Trunk weight is about ten times the leaf weight but is very variable, depending perhaps on how high the tree canopy has to be elevated to reach the light.

Just what size a research group should be for maximum efficiency has been the subject of surprisingly little research, and that mainly by non-scientists. The tree analogy suggests we should consider separately the best size for a research unit (branch size), department (tree size) and national research body (forest size). The last will be directly related to the size, resources or needs of the country, but there is no reason why tree size would be related to forest size. A research department will have an optimum size and structure depending on its Eunction just as different species of tree will vary in size and leaf form; and a large country should establish many trees of this size, so that each can adapt to its local environment, rather than try to grow an extra large one.

If the pursuit of efficiency is desirable, useful comparisons of productivity could be made between branches of similar size on the same tree. Caution is needed to check that the branches have similar function and aspect (access to resources), while comparisons between branches on different species of tree (department or discipline) will be meaningless until some way is found of balancing their diverse aims or products. The most profitable comparisons are likely to be between branches on similar trees; for example, gamebird research units of state wildlife departments in America.

Administrators may argue that they are not dead wood but a structural device like a tree trunk to increase size, allowing successful competition with other ever-expanding trees, and enabling their research units to find a place in the sun. This, however, might be better achieved by cutting out the big trees and replacing them with smaller, more productive young ones, as any forester knows.

Before the axe falls there are the usual ecological provisos: agreement on the kinds of trees to fell and which to plant, retention of unusual trees whose genotype might be useful in future, maintenance of variety and mixed age distributions for stability, and a reserve for such giant redwoods as the National Health Service. Yours faithfully,

230 Hill Road, JoHN E. C. FLUX

Belmont, Lower New Zealand.

\section{Merrison's malady}

SIR - That the Merrison Committee cannot resolve the malaise afflicting university research is clear enough (leading article, 22 May).

It is the readiness of our administrators to act as Healey-Joseph monetarist surgeons that has brought the malaise to this critical stage. The universities, in shedding technical and research posts, or equipment renewal and repair costs, have expected the research grant bodies to pick them up. The research councils, faced with impossible demands on static and contracting budgets, have resorted to financia limits apparently "calculated to ensure that even the best projects will not quite succeed" and to arbitrary time limits (such as the SRC's new ban on individuals holding an RA post for more than three or, exceptionally, six years).

Partly because we lack political muscle and partly because research jobs are regarded as transitory, contract researchers are being treated as optional extras - hard luck on personnel employed for years on soft money or unable to find a British university home to develop possibly outstanding projects. There are, however, some 10,000 contract workers in universities (Association of University Teachers figures) compared with 30,000 teaching staff. A proportion of university research of the order of 40 per cent might fairly be attributed to us.

Quality is relevant too. Experienced researchers are invaluable and irreplaceable for certain projects. Six or ten-year space research projects cannot be run by a succession of three-year contract researchers. To get round the SRC time limit, special dispensatins for 'project managers' are currently being sought; but such subterfuge cannot meet the need for experienced instrument designers and data analysts. Already some space projects are threatened with run-down. Expensive equipment will be unused and expensivelyaccumulated data will remain in store.

As you say,the Merrison joint committee between research councils and the UGC cannot be expected to discover a solution for the distribution of severely reduced funds. With only top academics and administrators, and no representatives of researchers or their trade unions, how could the seven-man (all male) working party invent an acceptable bargaining structure?

Surely the aim should instead be to analyse the malaise and conceive a holding operation; to persuade the UGC that it should not and cannot meet Government targets by cutting equipment grants, but must restore them with proper compensation for inflation, and to persuade the research councils to keep alive university laboratories and research teams.

Research itself will only suffer more from further surgery and hacking off weaker and less glamorous sectors. The holding operation should aim to maintain the successful integration of research in British universities until the government which conceives targets in monetary terms alone can be changed. Yours faithfully,

M.K. Wallis

University College, Cardiff, UK 